\title{
Case Report Medical Eponyms
}

\section{An Applied Clinical Informatics Opportunity}

L.N. Guptha Munugoor Baskaran ${ }^{1,2,5}$;P.J. Greco ${ }^{1,2,5}$; D.C. Kaelber ${ }^{1,2,3,4,5}$

${ }^{1}$ Departments of Information Systems; ${ }^{2}$ Internal Medicine; ${ }^{3}$ Pediatrics; ${ }^{4}$ Epidemiology, and Biostatistics; ${ }^{5}$ Center for Clinical Informatics Research and Education; The MetroHealth System and School of Medicine, Case Western Reserve University, Cleveland $\mathrm{OH}$

\section{Keywords}

Medical eponyms, electronic health records, integrated clinical decision support, patient safety, system improvement

\section{Summary}

Medical eponyms are medical words derived from people's names. Eponyms, especially similar sounding eponyms, may be confusing to people trying to use them because the terms themselves do not contain physiologically descriptive words about the condition they refer to. Through the use of electronic health records (EHRs), embedded applied clinical informatics tools including synonyms and pick lists that include physiologically descriptive terms associated with any eponym appearing in the EHR can significantly enhance the correct use of medical eponyms. Here we describe a case example of two similar sounding medical eponyms - Wegener's disease and Wegner's disease which were confused in our EHR. We describe our solution to address this specific example and our suggestions and accomplishments developing more generalized approaches to dealing with medical eponyms in EHRs. Integrating brief physiologically descriptive terms with medical eponyms provides an applied clinical informatics opportunity to improve patient care.

\section{Correspondence to}

David C Kaelber, MD, PhD, MPH

3158 Kingsley Road

Shaker Heights $\mathrm{OH} 44122$

David.kaelber@case.edu

216-409-0538
Appl Clin Inf 2012; 3: 349-355

doi:10.4338/ACl-2012-05-CR-0019

received: June 19, 2012

accepted: August 29, 2012

published: September 26, 2012

Citation: Guptha Munugoor Baskaran LN, Greco PJ, Kaelber DC. Case report medical eponyms - an applied clinical informatics opportunity. Appl Clin Inf 2012; 3: 349-355

http://dx.doi.org/10.4338/ACl-2012-05-CR-0019 


\section{Introduction}

Eponyms are words or terms derived from people's names. Medical eponyms have been used for centuries for identification and scientific recognition (sometimes erroneously) of various medical diseases, syndromes, methods, process, substances, organs, organ parts, signs and symptoms. Approximately 8,000 medical eponyms exist today $[1,2]$.

There are pros and cons to the use of medical eponyms $[3,4]$. However, what appears clear is that medical eponyms will continue to be used in clinical medicine for the foreseeable future. Moreover, errors in the use of medical eponyms will continue because some people who use a medical eponym, especially similar sounding medical eponyms, will use them incorrectly $[5,6]$. This incorrect use of medical eponyms stems, at least in part, from the fact that the eponym does not include physiologically descriptive terms. Additionally, even if the medical eponym is used correctly, others seeing only the eponym name itself many not know what the eponym is referring to. These issues present an applied clinical informatics opportunity.

\section{Case}

As part of a larger project to automate the mandatory reports of diseases for public health purposes between our electronic health record (EHR) and our state disease reporting system [7, 8, 9], we were trying to identify patients with syphilis. Therefore, we were examining encounter diagnosis and problem list ICD-9 codes in our Epic EHR (Epic Systems Corporation, Verona WI) related to syphilis from 2009-2011.

We discovered six patients out of 57 over a 2-year period that had an ICD-9 code description related to syphilis (congenital syphilitic osteochondritis). However, on manual validation review of their EHR records, these patients did not have laboratory conformation or other documentation corroborating the syphilis ICD-9 code description. Rather, these six patients had documentation corroborating a diagnosis of a vasculitis - Wegener's Granulomatosis. While the clinicians were trying to add Wegener's disease (Wegener's Granulomatosis) to the patient's diagnosis or problem list, they were actually adding Wegner's disease (congenital syphilis osteochondritis) to the patient's diagnosis or problem list. Wegener's Granulomatosis is a disorder in which small and medium blood vessels develop vasculitis and has nothing to do with syphilis. We found two patients who had an ICD-9 code for Wegner's disease incorrectly listed in their problem list and four patients who had an ICD-9 code for Wegner's disease incorrectly listed in their encounter diagnoses. There were a total of 37 encounters for these six patients in which the incorrect ICD-9 codes were used. Outside of our operational, non-research efforts to identify and correct these incorrect ICD-9 codes we did not involve any human subject or their data in this research. Therefore, no IRB approval was sought or obtained for this work.

\section{Results}

Once discovered, to avoid this problem in the future, whenever the ICD-9 code description for Wegner's disease appears in a structured ICD-9 pick list in our Epic EHR we changed our display name to the "long display name" option in our EHR and then added a long display name for Wegner's disease of "Wegner's disease (congenital syphilitic osteochondritis)" ( $>$ Fig. 1). In the first year since this change, we are not aware of any cases of the ICD-9 code for Wegner's disease being mistakenly used for the ICD-9 code of Wegener's disease in our EHR.

Although this change to our local EHR system addressed this issue in our healthcare system, we also looked to broaden the impact of this informatics intervention to improve the correct use of medical eponyms in two additional ways;

1. identifying other potential eponym examples and

2. embedding eponym physiologically descriptive information with our third party knowledge vendor. 
We searched for other similar sounding but different meaning medical eponyms from within the standard ICD-9 CM data set [10] on two different medical eponyms sites [1,2]. Additionally, we reviewed our EHR diagnosis records to look for diagnoses that met the following three criteria

1. whose name contained the terms "syndrome" or "disease",

2. were actually used at least one time as a billing diagnosis in our EHR, and

3. were valid (as opposed to retired) ICD-9 CM billing diagnoses.

Finally, we also queried the Unified Medical Language System (UMLS) Medical Subject Headings $(\mathrm{MeSH})$ looking for similar sounding but different meaning terms whose name contained the terms "syndrome" or "disease" [11]. These analyses led to identifying other similar clinically relevant examples of pairs (two) or groups (more than two) of similar sounding, but significantly different meaning eponyms. For each pair or group of similar sounding but different meaning eponyms we developed a brief (less than 55 characters in length) physiological description for each eponym $(\triangleright$ Table 1$)$.

Secondly, to broaden the impact of our solution and make this intervention easier for multiple different EHRs across different healthcare systems to implement, we wanted to approach our third party terminology vendor. Therefore, we contacted Intelligent Medical Objects $\left(\mathrm{IMO}^{\circledR}\right)$ (http://www.e-imo.com) (Northbrook IL), the terminology vendor that we use for problem/diagnosis terms and codes and provides mapping to ICD-9. $\mathrm{IMO}^{\circledR}$ was receptive to integrating brief physiological descriptive term (s) in their ICD-9 CM eponym terms with similar sounding eponyms that were identified and has already integrated in brief physiological descriptive terms for all eponyms in $>$ Table 1 with their August 2012 update. This way any customer, including ourselves, who used the $\mathrm{IMO}^{\circledR}$ Problem (IT) product, have, at least for this group of similar sounding eponyms, the eponym's brief physiologically descriptive term(s) automatically installed and maintained as part of their normal use of the $\mathrm{IMO}^{\circledR}$ Problem (IT) product. Physiological descriptive terms would also have some value for eponyms without similar sounds eponyms and could use this model.

\section{Discussion}

With approximately 8,000 medical eponyms in existence today, medical eponyms are an important part of the clinical lexicon $[1,2]$. However, medical eponyms, because they do not contain physiological descriptions, are sometimes used inappropriately $[5,6]$. Even when used appropriately, medical eponyms can cause confusion because others seeing the eponym may not know or understand their meaning.

One of the promises of applied clinical informatics is to provide point of care information integrated into the clinical work flow - the right information, to the right person, in the right format, through the right channel, and at the right time point in the workflow [12]. The info button provides one approach to this [13]. However, for medical eponyms we provide an alternative information integration approach by integrating additional information in with the name of the eponym in ICD-9 structured pick lists. This approach eliminates the extra info button click and makes the additional information describing the eponym even easier to appreciate. This approach could also be taken with any terminology that includes medical eponyms, for example ICD-10 [14] and SNOMED-CT [15]. Including brief physiological descriptions anywhere an eponym occurs will help with appropriate use and easier understanding of eponyms that appear in these terminologies.

Our approach of engaging a third-party terminology vendor in this solution makes it very scalable so that others will benefit from this information support with no significant additional effort on their part if they already use a third-part terminology vendor. The keys to addressing this eponym issue are

- to make sure those terminology vendors and organizations that create and maintain terminologies include brief physiological descriptions with any eponyms in their terminology and

- that EHR software vendors (and any other product vendor that presents terminologies to end users) configure their products to easily accommodate eponyms with brief physiological descriptions. 
This case example and solution approach will hopefully improve the use of eponyms, especially similar sounding eponyms, in numerous EHRs, as it already has in our EHR. Hopefully this example will also stimulate people to think of other situations and approaches to further integrating point of care information support into EHRs.

\section{Conclusion}

Medical eponyms provide an opportunity to take basic clinical informatics principles and tools clinical terminology ontologies and clinical decision support - and integrate them into actual clinical information systems to improve clinical care. Coupling brief physiological descriptions with eponym names, especially those with similar sounding eponym names, when they appear in structured pick lists in EHRs provides integrated point of care clinical decision support to enhance correct use of medical eponyms and thereby improve patient care.

\section{Clinical Relevance Statement}

This case report identifies an opportunity that all electronic health records (EHR) users and EHR vendors, as well as third-party EHR knowledge/terminology vendors/providers can use to incorporate brief physiological descriptions with medical eponyms names, especially those with similar sounding eponyms, to improve patient care.

\section{Authors' Contribution}

All authors were involved in the evaluations of the eponyms discussed in this manuscript. All authors were also involved in the writing and review of this manuscript.

\section{Conflict of Interest}

No authors had any conflict of interest related to this work. No external funding was involved in the work.

\section{Acknowledgements}

The authors are appreciative of Intelligent Medical Objects Corporation for their input in assisting with the short physiological eponym descriptions that appear in $\$ Table 1 and their willingness to enhance their IMO ${ }^{\circledR}$ Problem (IT) product to address the similar sounding eponyms issue raised in this case report.

\section{Protection of Human Subjects and Animals in Research}

This work did not involve any interventions in human or animal subjects. 


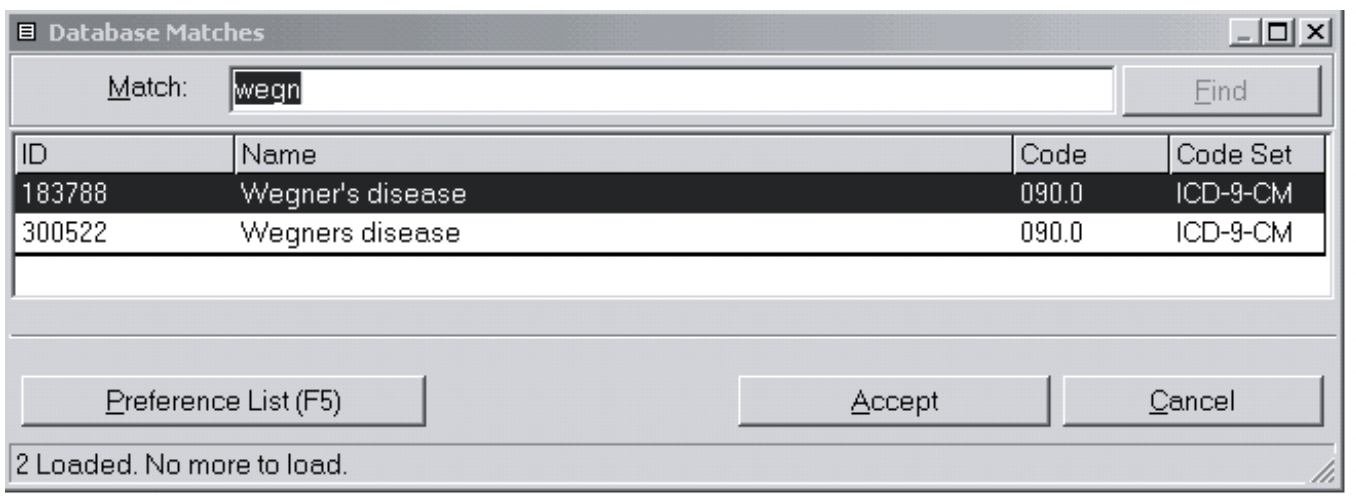

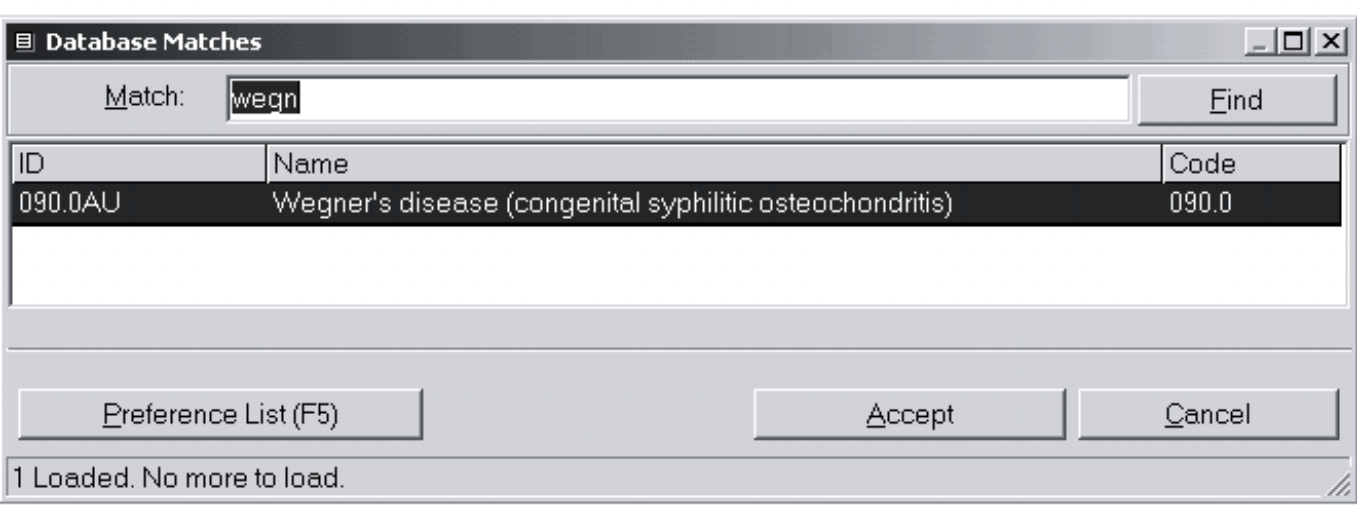

Fig. 1 Screen shots of Wegner's Disease eponym in our electronic health record from ICD-9 CM pick lists before (upper) and after (lower) including integrated short physiological description. 
Table 1 Examples of similar sounding eponym pairs (or triples) referring to different clinical conditions (possible short physiological descriptions in italics).

\begin{tabular}{|c|c|c|}
\hline $\begin{array}{l}\text { Albright syndrome } \\
\text { (infant renal tubular acidosis) }\end{array}$ & $\begin{array}{l}\text { McCure-Albright syndrome } \\
\text { (polyostotic fibrous bone dysplasia) }\end{array}$ & $\begin{array}{l}\text { Albright's anemia } \\
\text { (anemia associated with } \\
\text { hyperparathyroidism) }\end{array}$ \\
\hline $\begin{array}{l}\text { De Quervain disease } \\
\text { (radial styloidc tenosynovitis) }\end{array}$ & $\begin{array}{l}\text { De Quervain's syndrome } \\
\text { (complete testicular feminization) }\end{array}$ & \\
\hline $\begin{array}{l}\text { Frey's syndrome } \\
\text { (gustatory sweating) }\end{array}$ & $\begin{array}{l}\text { Frei's disease } \\
\text { (lymphogranuloma venereum) }\end{array}$ & \\
\hline $\begin{array}{l}\text { Hunt's disease } \\
\text { (occupational compression of ulnar nerve) }\end{array}$ & $\begin{array}{l}\text { Hunt's syndrome } \\
\text { (cerebellar dyssyndergia with interntion } \\
\text { tremor and myoclonus) }\end{array}$ & $\begin{array}{l}\text { Ramsay Hunt Syndrome } \\
\text { (geniculate herpes zoster) }\end{array}$ \\
\hline $\begin{array}{l}\text { Meigs' syndrome } \\
\text { (ovarian fibroma with ascites and pleural } \\
\text { effussion) }\end{array}$ & $\begin{array}{l}\text { Meige's syndrome } \\
\text { (blepharospasm with oromandibular } \\
\text { dystonia) }\end{array}$ & $\begin{array}{l}\text { Meige's disease } \\
\text { (lymphedema praecox) }\end{array}$ \\
\hline $\begin{array}{l}\text { Meniere's disease } \\
\text { (cochlear hydrops) }\end{array}$ & $\begin{array}{l}\text { Menetrier's disease } \\
\text { (hyperplastic hypersecretory gastrophy) }\end{array}$ & \\
\hline $\begin{array}{l}\text { Paget's Disease of bone } \\
\text { (osteitis deformans) }\end{array}$ & $\begin{array}{l}\text { Paget's Disease of breast } \\
\text { (epidermal malignancy of nipple and } \\
\text { areola) }\end{array}$ & $\begin{array}{l}\text { Paget's Disease of vulva } \\
\text { (intraepithelial adenoc- } \\
\text { arcinoma) }\end{array}$ \\
\hline $\begin{array}{l}\text { Pott's disease } \\
\text { (spinal tuberculosis) }\end{array}$ & $\begin{array}{l}\text { Pott's puffy tumor } \\
\text { (frontal bone osteomyelitis with sub- } \\
\text { periosteal abscess) }\end{array}$ & $\begin{array}{l}\text { Pott's fracture } \\
\text { (of distal fibula) }\end{array}$ \\
\hline $\begin{array}{l}\text { Wegener's granulomatosis } \\
\text { (granulomatosis with polyangiitis) }\end{array}$ & $\begin{array}{l}\text { Wegner's disease } \\
\text { (congenital syphilitic osteochondritis) }\end{array}$ & \\
\hline $\begin{array}{l}\text { Wermer's syndrome } \\
\text { (multiple endocrine neoplasms, type 1) }\end{array}$ & $\begin{array}{l}\text { Werner's syndrome } \\
\text { (hereditary premature aging) }\end{array}$ & \\
\hline
\end{tabular}




\section{References}

1. Enersen O D. Whonamedit - A dictionary of medical eponyms [Internet]. c1994-2012 [cited 27 April 2012]. Available from http://www.whonamedit.com/.

2. Yee A. Andrew Yee's medical eponym page [Internet]. c2000-2012 [updated 10 August 2008; cited 27 April 2012]. Available from http://eponyms.net/..

3. Woywodt A, Matteson E. Should eponyms be abandoned? Yes. BMJ 2007; 335: 424.

4. Whitworth JA. Should eponyms be abandoned? No. BMJ 2007; 335: 425.

5. Matteson EL, Woywodt A. Eponymophilia in rheumatology. Rheumatology 2006; 45: 1328-1330.

6. Waseem M, Khan M, Hussain N, Giannoudis PV, Fischer J, Smith RM. Eponyms: errors in clinical practice and scientific writing. Acta Orthop Belg 2005; 71: 1-8.

7. Lazarus R, Klompas M, Campion FX, McNabb SJN , Hou X, Daniel J et al. The practice of informatics: viewpoint paper: electronic support for public health: validated case finding and reporting for notifiable diseases using electronic medical data. JAMIA 2009; 16: 18-24. doi:10.1197/jamia.M2848.

8. Klompas M, Lazarus R, Daniel J, Haney GA, Campion FX, Kruska BA et al. Automated detection and reporting of notifiable diseases using electronic medical records versus passive surveillance. MMWR Weekly 2008; 57(14): 373-376.

9. Klompas M, Lazarus R, Daniel J, Haney GA, Campion FX, Kruska BA et al. Electronic medical record support for public health (ESP): automated detection and reporting of statutory notifiable diseases to public health authorities. Advances in Disease Surveillance 2007; 3: 3.

10. Centers for Disease Control and Prevention. International Classification of Disease, Ninth Revision, Clinical Modification (ICD-9-CM). CDC/National Center for Health Statistics Office of Information Services. c2012 [updated 23 September 2011; cited 04 April 2012]. Available from: http://www.cdc.gov/nchs/icd/ icd $9 \mathrm{~cm} . h \mathrm{htm}$.

11. Unified Medical Language System (UMLS) Medical Subject Headings (MeSH). US National Library of Medicine, National Institutes of Health, Department of Health and Human Services. c1993-2012 [updated 28 August 2011; cited 05/13/2012]. Available from: http://www.nlm.nih.gov/mesh/MBrowser.html.

12. Osheroff JA, Teich JM, Levick D, Saldana L, Velasco FT, Sittig DF, et al. Improving outcomes with clinical decision support: An implementer's guide. Second edition. HIMSS. 2012.

13. Collins SA, Currie LM, Bakken S, and Cimino JJ. Case report: information needs, infobutton manager use, and satisfaction by clinician type: a case study. JAMIA 2009; 16: 140-142.

14. The World Health Organization. International Statistical Classification of Diseases and Related Health Problems, 10th Revision: 2010. c2012 [cited 07/07/2012]. Available from: http://apps.who.int/classifi cations/icd10/browse/2010/en.

15. International Health Terminology Standards Development Organisation. Integrated Terminology ServerSystematized Nomenclature of Medicine (SNOMED) Clinical Terms Version: 20120131. c2002-2012 [updated 1/2012; cited 07/07/2012]. Available from: http://www.itserver.es/ITServer/Browser/snomedct browser.faces. 